\title{
Introductory Remarks from the Guest Editors
}

\author{
G. N. Kulipanov • B. A. Knyazev • A. P. Shkurinov
}

Received: 25 August 2011 / Accepted: 13 September 2011/

Published online: 4 October 2011

(C) The Author(s) 2011. This article is published with open access at Springerlink.com

With great pleasure we present a special issue entitled «THz summer 2010 in Russia» in the «International Journal of Infrared and Millimeter Waves». The idea of publishing this Issue arose after the International Symposium «Terahertz radiation: Generation and Application» held in Novosibirsk, July, 26-31, 2010 which for the first time in Russia brought together scientists from different fields whose subject of research falls into the terahertz frequency range. The Issue includes twelve papers, which were first presented as plenary and invited talks at several conferences and symposia held in 2010 in Russia. Despite its moderate volume the papers comprehensively show the modern trends of this field in Russia. The first Special issues devoted to up-to-date topics of terahertz optics, optoelectronics and spectroscopy date back to 2009-2010 when they were published in "Optics and Spectroscopy" Journal (vol. 107, N4 and vol. 108, N6).

The Russian scientific community working in this area is growing considerably every year because young scientists join this field, research groups are created and collaborate intensly with other research groups worldwide. It becomes evident that this dynamically growing scientific field has evoked interest of the Russian scientific community. Researches and engineers from adjacent field of knowledge have been actively looking for ways of using of electromagnetic radiation in the terahertz frequency range in earlier developed optical technologies in order to obtain new knowledge and new materials.

Open Access This article is distributed under the terms of the Creative Commons Attribution Noncommercial License which permits any noncommercial use, distribution, and reproduction in any medium, provided the original author(s) and source are credited.

G. N. Kulipanov $\cdot$ B. A. Knyazev

Budker Institute of Nuclear Physics, Siberian Branch of Russian

Academy of Science, Novosibirsk, Russia

A. P. Shkurinov $(\bowtie)$

M. V. Lomonosov Moscow State University, Moscow, Russia 